\title{
Moods and Attitude Judgments: A Comment on Fishbein and Middlestadt
}

\author{
Norbert Schwarz \\ Institute for Social Research and Department of Psychology \\ University of Michigan
}

\begin{abstract}
Fishbein and Middlestadt (F \& M; 1995) proposed that all "noncognitive" influences on attitude change are mediated through changes in beliefs and their evaluative implications. This proposal is evaluated in light of recent research into different processes underlying mood effects on attitude judgments. Whereas some process assumptions (mood congruent recall and mood-induced differences in processing style) are compatible with F \& M's proposal, other influences cannot be traced to changes in belief structure. Instead, individuals' mood at the time of judgment may itself serve as a source of information, resulting in direct influences on evaluative judgments.
\end{abstract}

Fishbein and Middlestadt (F \& M; 1995) offered a defense of belief-based models of attitude formation and change and raised a number of interesting questions regarding the role of "noncognitive" factors. Specifically, they asked,

How do a variety of noncognitive factors, such as peripheral cues, cognitive heuristics, emotional reactions, affective responses, classically conditioned reactions, and attitudes towards messages, exert an influence? Do these other factors influence attitudes only indirectly, through their impact on the cognitive structure ... or is there evidence for a direct link between these other factors and attitude change? (pp. 183-184)

Although most researchers would consider the bulk of these sources of information to be cognitive, F \& M restrict the use of the term cognitive to "beliefs and their evaluative aspects" (p. 185). As a result, peripheral cues (such as the expertise of a communicator), cognitive heuristics (such as, "more arguments are better"), evaluations of the message (such as attitudes toward the ad) and related variables

Requests for reprints should be sent to Norbert Schwarz, Institute for Social Research, University of Michigan, Ann Arbor, MI 48106-1248. E-mail: NSchwarz@umich.edu 
are classified as noncognitive, along with emotional reactions, affective responses, and conditioned reactions (p. 184). Of course, what is to be considered cognitive and what not has been the topic of considerable debate in response to Zajonc's (1980) proposition that preferences need no inferences, but this debate needs no reiteration. Rather, I focus on the impact of a clearly affective variable-namely, individuals' mood at the time of judgment. Specifically, I review research into the impact of induced temporary moods on attitude judgments and ask whether mood effects reflect a "direct" influence or are mediated through their impact on cognitive structure. Recent research in social cognition indicates that individuals in a happy mood report more positive attitudes than individuals in a sad mood. Moreover, moods may influence how individuals process persuasive messages. I address both aspects in turn.

\section{MOOD AND ATTITUDE JUDGMENTS}

Numerous studies demonstrate that individuals' affective states may influence a wide range of evaluative judgments, ranging from satisfaction with consumer goods and the evaluation of other persons, selected activities, or past life-events to reports of happiness and satisfaction with one's life as a whole (see Clore, Schwarz, \& Conway, 1994; Schwarz \& Clore, 1996, for reviews). Throughout, individuals report more positive attitudes when in an induced happy mood rather than sad mood. Two models have been offered to account for these effects.

One model maintains that moods increase the cognitive accessibility of mood congruent material in memory (e.g., Bower, 1981; Isen, Shalker, Clark, \& Karp, 1978). As a result, positive aspects of the attitude object are more likely to come to mind under happy rather than sad mood conditions, resulting in a mood congruent judgment. This model clearly holds that mood effects are mediated by the impact of moods on cognitive structure in F \& M's sense of "beliefs and their evaluative implications" (p. 185). However, mood congruent retrieval is a rather fragile phenomenon that is most likely to be obtained for poorly structured autobiographical material (see Blaney, 1986; Clore et al., 1994, for reviews), whereas mood effects on judgment are highly robust. Moreover, mood effects on judgments have often shown patterns that are incompatible with predictions derived from mood congruent recall models, as addressed next.

An alternative model traces mood effects on judgment to the informative functions of affective states. Rather than computing a judgment on the basis of recalled features of the target, individuals may use their apparent affective reaction to the target as relevant information when making evaluative judgments, essentially asking themselves, "How do I feel about it?" (Schwarz \& Clore, 1983, 1988). In doing so, however, they may mistake feelings due to a preexisting mood state as a reaction to the target stimulus, resulting in more positive evaluations under pleasant 
than under unpleasant moods. If so, the impact of affective states on attitude judgments should depend on the state's perceived informational value. If individuals attribute their current feelings to a source that is irrelevant to the evaluation of the target stimulus, the informational value of their affective state should be discredited and their feelings should not influence the evaluative judgment. In line with this hypothesis, Schwarz and Clore (1983) observed that the impact of mood on judgments of life satisfaction was eliminated when participants attributed their current feelings either correctly (Experiment 2) or incorrectly (Experiment 1) to a transient source. For example, participants reported higher life satisfaction and a more elated mood in telephone interviews when called on sunny days rather than rainy days. The impact of mood on life-satisfaction was eliminated, however, when the interviewer mentioned the weather as part of a private aside, thus directing participants' attention to this source of their elated or depressed state (Experiment 2). In addition, current mood, as assessed at the end of the experiment, was more strongly correlated with judgments of life satisfaction when participants' attention was not directed to a transient source of their feelings than when it was.

Findings of this type (see Clore et al., 1994; Schwarz \& Clore, 1996, for reviews and Pham, 1994, for applications to consumer research) indicate that individuals may use their current feelings as a basis of judgment unless the diagnostic value of their feelings for the judgment at hand is called into question. This discounting effect (Kelley, 1972) is incompatible with models of mood congruent recall (Bower, 1981; Isen et al., 1978), discussed previously in this article. Note that the (mis)attribution manipulations used by Schwarz and Clore (1983) only discredited the implications of one's current feelings, but not the implications of valenced information about one's life, which may have been recalled from memory. Being aware that one's current bad mood may be due to the lousy weather implies that it may not reflect an overall negative state of one's life. This attribution, however, does not discredit the implications of any recalled failures, for example.

What does the feelings-as-information perspective imply for F \& M's question about the role of noncognitive factors in attitude judgments? As the previous discussion indicates, this approach treats moods and other feelings as sources of information, thus blurring the distinction between cognitive and noncognitive factors, and traces the influence of subjective experiences like moods (e.g., Schwarz \& Clore, 1983), bodily reactions (e.g., Strack, Martin, \& Stepper, 1988), feelings of familiarity (e.g., Jacoby, Kelley, Brown, \& Jasechko, 1989), or experienced ease of recall (e.g., Schwarz, Bless, Strack, et al., 1991) to their informational value (see Clore, 1992; Schwarz \& Clore, 1996; Strack, 1992, for reviews). Although this conceptualization of the interplay of feeling and thinking may strike many as highly cognitive (see Zajonc, 1980), it is not compatible with the overly narrow conceptualization offered by $\mathrm{F} \& \mathrm{M}$, who essentially equate "cognitive processes" with the limited set of operations posited by expectancy-value models (see F \& M, 1995, p. 199). 


\section{MOOD AND THE PROCESSING OF PERSUASIVE MESSAGES}

In addition to serving as relevant information in forming evaluative judgments, moods may influence the choice of processing strategies. Compared to individuals in a neutral mood, individuals in a happy mood are more likely to rely on heuristic processing strategies, whereas individuals in a sad mood are more likely to rely on systematic processing strategies (see Clore et al., 1994; Schwarz \& Clore, 1996, for reviews). This influence can again be traced to the informative functions of affective states (Schwarz, 1990). In a nutshell, we feel good when our current environment poses no problem, but we feel bad when it does. The relation between our assessment of our environment and our feelings, however, is bidirectional. Hence, feeling good informs us that our environment is benign, whereas feeling bad informs us that our environment poses a problem. In dealing with problems, however, it is adaptive to pay close attention to details and to engage in a systematic, bottom-up processing strategy. In contrast, benign situations require less attention to detail and allow us to rely on general knowledge structures, thus fostering heuristic, top-down processing strategies. The resulting differences in processing style have been observed in a wide variety of content domains, including person perception (for a review, see Sinclair \& Mark, 1992), stereotyping (for a review, see Bless, Schwarz, \& Kemmelmeier, 1996), and persuasion (for a review, see Schwarz, Bless, \& Bohner, 1991), as well as the encoding of other social information (e.g., Bless, Clore, et al., 1996).

In the persuasion domain, for example, individuals in a happy mood have been found to be equally persuaded by strong and weak arguments, reflecting that they did not engage in "systematic" (Chaiken, Liberman, \& Eagly, 1989) or "central route" (Petty \& Cacioppo, 1986) message processing. In contrast, individuals in a sad mood have been found to be persuaded by strong arguments but not by weak arguments, indicating that they did engage in systematic message processing. Importantly, these effects of mood on processing style are again eliminated when individuals are induced to attribute their mood to an irrelevant source, unrelated to the message (Sinclair, Mark, \& Clore, 1994). These affective influences on processing style, in turn, influence the resulting cognitive representation of the message. Their impact on attitude change can therefore be traced to changes in cognitive structure. Accordingly, the differential attitude change resulting from mood effects on processing style is generally compatible with F \& M's conclusions, although the underlying processes differ from the specifics addressed by F \& $M$.

\section{CONCLUSIONS}

As my comments indicate, mood effects on attitude judgments are pervasive and may take a number of different forms (see also Forgas, 1992). First, moods may 
facilitate the recall of mood congruent material from memory, thus rendering different "beliefs" accessible. Second, moods may influence individuals' processing style, resulting in different mental representations of the target. Both of these influences are compatible with $\mathrm{F} \& \mathrm{M}$ 's assumption that affective influences are mediated by changes in individuals' cognitive structure (i.e., "beliefs and their evaluative implications"; F \& M, 1995, p. 185). As a third possibility, however, moods and other feelings may themselves serve as a source of information that individuals draw on, unless their diagnostic value is called into question. These influences are not mediated by belief changes of the type addressed by F \& M. Yet, much as it is difficult to determine the boundaries between affect and cognition (as the Zajonc-Lazarus debate illustrated), it is only a small step from treating feelings as information to subsuming the information that they provide under a broader conceptualization of beliefs. Unfortunately, such attempts to reduce all judgmental processes to the limited number of inputs and operations allowed by expectancyvalue models are unlikely to contribute much to our understanding of the processes underlying the interplay of affect and cognition in attitude judgments.

\section{REFERENCES}

Blaney, P. H. (1986). Affect and memory: A review. Psychological Bulletin, 99, 229-246.

Bless, H., Clore, G. L., Schwarz, N., Golisano, V., Rabe, C., \& Wölk, M. (1996). Mood and the use of scripts: Does being in a happy mood really lead to mindlessness? Journal of Personality and Social Psychology, 71, 665-679.

Bless, H., Schwarz, N., \& Kemmelmeier, M. (1996). Mood and stereotyping: The impact of moods on the use of general knowledge structures. European review of social psychology, 7, 63-93.

Bower, G. H. (1981). Mood and memory. American Psychologist, 36, 129-148.

Chaiken, S., Liberman, A., \& Eagly, A. H. (1989). Heuristic and systematic information processing within and beyond the persuasion context. In J.S. Uleman \& J. A. Bargh (Eds.), Unintended thought: Limits of awareness, intention, and control (pp. 212-252). New York: Guilford.

Clore, G. L. (1992), Cognitive phenomenology: Feelings and the construction of judgment. In L. L. Martin \& A. Tesser (Eds.), The construction of social judgment (pp. 133-164). Hillsdale, NJ: Lawrence Erlbaum Associates, Inc.

Clore, G. L., Schwarz, N., \& Conway, M. (1994). Cognitive causes and consequences of emotions. In R. S. Wyer \& T. K. Srull (Eds.), Handbook of social cognition (2nd ed., pp. 323-417). Hillsdale, NJ: Lawrence Erlbaum Associates, Inc.

Fishbein, M., \& Middlestadt, S. (1995). Noncognitive effects on attitude formation and change: Fact or artifact? Journal of Consumer Psychology, 4, 181-202.

Forgas, J. P. (1992). Affect in social judgments and decisions: A multi-process model. In M. P. Zanna (Ed.), Advances in experimental social psychology (Vol. 25, pp. 227-275). San Diego: Academic.

Isen, A. M., Shalker, T. E., Clark, M. S., \& Karp, L. (1978). Affect, accessibility of material in memory, and behavior: A cognitive loop? Journal of Personality and Social Psychology, 36, 1-12.

Jacoby, L. L., Kelley, C. M., Brown, J., \& Jasechko, J. (1989). Becoming famous overnight: Limits on the ability to avoid unconscious influences of the past. Journal of Personality and Social Psychology, $56,326-338$. 
Kelley, H. H. (1972). Causal schemata and the attribution process. Morristown, NJ: General Learning Press.

Petty, R. E., \& Cacioppo, J. T. (1986). The elaboration likelihood model of persuasion. In L. Berkowitz (Ed.), Advances in experimental social psychology (Vol. 19, pp. 124-205). New York: Academic.

Pham, T. (1994). Feeling like consuming: Affect as information in decisions about consumption episodes. Unpublished doctoral dissertation, University of Florida, Gainesville.

Schwarz, N. (1990). Feelings as information: Informational and motivational functions of affective states. In E. T. Higgins \& R. Sorrentino (Eds.), Handbook of motivation and cognition: Foundations of social behavior (Vol. 2, pp. 527-561). New York: Guilford.

Schwarz, N., Bless, H., \& Bohner, G. (1991). Mood and persuasion: Affective states influence the processing of persuasive communications. In M. Zanna (Ed.), Advances in experimental social psychology (Vol. 24, pp. 161-199). San Diego: Academic.

Schwarz, N., Bless, H., Strack, F., Klumpp, G., Rittenauer-Schatka, H., \& Simons, A. (1991). Ease of retrieval as information: Another look at the availability heuristic. Journal of Personality and Social Psychology, 61, 195-202.

Schwarz, N., \& Clore, G. L. (1983). Mood, misattribution, and judgments of well-being: Informative and direct ve functions of affective states. Journal of Personality and Social Prychology, 45, 513-523.

Schwarz, N., \& Clore, G. L. (1988). How do I feel about it? Informative functions of affective states. In K. Fiedler \& J. Forgas (Eds.), Affect, cognition, and social behavior (pp. 44-62). Toronto: Hogrefe International.

Schwarz, N., \& Clore, G. L. (1996). Feelings and phenomenal experiences. In E. T. Higgins \& A. Kruglanski (Eds.), Social psychology: Handbook of basic principles (pp. 433-465). New York: Guilford.

Sinclair, R. C., \& Mark, M. M. (1992). The influence of mood state on judgment and action: Effects on persuasion, categorization, social justice, person perception, and judgmental accuracy. In L. L. Martin \& A. Tesser (Eds.), The construction of social judgment (pp. 165-193). Hillsdale, NJ: Lawrence Erlbaum Associates, Inc.

Sinclair, R. C., Mark, M. M., \& Clore, G. L. (1994). Mood-related persuasion depends on misattributions. Social Cognition, 12, 309-326.

Strack, F. (1992). The different routes to social judgments: Experiential versus informational strategies. In L. L. Martin \& A. Tesser (Eds.), The construction of social judgments (pp. 249-276). Hillsdale, NJ: Lawrence Erlbaum Associates, Inc.

Strack, F., Martin, L. L., \& Stepper, S. (1988). Inhibiting and facilitating conditions of the human smile: A nonobtrusive test of the facial feedback hypothesis. Journal of Personality and Social Psychology, $54,768-777$.

Zajonc, R. B. (1980). Feeling and thinking. Preferences need no inferences. American Psychologist, 35 , 151-175.

Accepted by Dipankar Chakravarti and Paul M. Herr. 